\title{
Enrichment, isolation and characterization of fungi tolerant to 1-ethyl-3- methylimidazolium acetate
}

\author{
Steven W. Singer ${ }^{1,2 *}$, Amitha P. Reddy ${ }^{1,4}$, John M. Gladden ${ }^{1,3}$, Hongyun Guo ${ }^{4}$, Terry C. Hazen ${ }^{1,2}$; \\ Blake A. Simmons ${ }^{1,5}$, Jean S. VanderGheynst ${ }^{1,4}$ \\ ${ }^{1}$ Joint BioEnergy Institute, Emeryville, CA 94608; ${ }^{2}$ Earth Science Division, Lawrence Berkeley National \\ Laboratory, Berkeley, CA 94720; ${ }^{3}$ Physical and Life Sciences Directorate, Lawrence Livermore National \\ Laboratory, 94551; ${ }^{4}$ Biological and Agricultural Engineering, University of California-Davis, 95616; \\ ${ }^{5}$ Biomass Science and Conversion Technology Department, Sandia National Laboratory, Livermore, CA, \\ 94551. \\ *Corresponding author: Steven W. Singer, Deconstruction Division, Joint Bioenergy Institute, 5885 Hollis \\ Street, Emeryville, CA 94608, Phone: (510) 495-2492,Fax: (510) 486-4252 \\ E-mail- SWSinger@lbl.gov
}

\begin{abstract}
Aims: This work aims to characterize microbial tolerance to 1-ethyl-3-methylimidazolium acetate ([C2mim][OAc]), ionic liquid that has emerged as a novel biomass pretreatment for lignocellulosic biomass.

Methods and Results: Enrichment experiments performed using inocula treated with [C2mim][OAc] under solid and liquid cultivation yielded fungal populationsdominated by Aspergilli. Ionic liquid-tolerant Aspergillus isolates from these enrichments were capable of growing in a radial plate growth assay in the presence of $10 \%$ [C2mim][OAc]. When a [C2mim][OAc]-tolerant Aspergillus fumigatus strain was grown in the presence of switchgrass, endoglucanases and xylanases were secreted that retained residual enzymatic activity in the presence

of $20 \%$ [C2mim][OAc].

Conclusions: The results of the study suggest tolerance to ionic liquids is a general property of Aspergilli. Significance and Impact of the Study: Tolerance to an industrially important ionic liquid was discovered in a fungal genera that is widely used in biotechnology, including biomass deconstruction.
\end{abstract}

\section{Introduction:}

Lignocellulosic biomass is a potential renewable feedstock that is available for conversion to biofuels that will replace a substantial amount of the petroleum-based transportation fuels (Gomez et al. 2008). Currently, most first-generation biofuels are derived from agricultural food sources such as corn grain and soybeans. Lignocellulosic biomass, which includes agricultural residues (corn stover, rice straw), agricultural by-products (corn fibre, rice hulls and sugarcane bagasse), woody biomass (poplar, pine) and dedicated energy crops (Miscanthus, switchgrass), has a low impact on human food supplies (Blanch et al. 2008). Pretreatment of lignocellulosic biomass is required for efficient saccharification to generate monomeric sugars for biofuel production. Established chemical pretreatment technologies, such as dilute acid and ammonia fibre expansion, greatly improve the yields of sugar from enzymatic hydrolysis, but new advances in pretreatment are needed for industrial production of cellulosic biofuels (Yang and Wyman 2008). Recently, ionic liquids (Fig. 1) have demonstrated excellent promise as solvents for biomass dissolution and cellulose recovery (Swatloski et al. 2002; Turner et al. 2004). The recovered cellulose is enzymatically hydrolyzed to glucose at much faster rates than observed for dilute acid pretreated biomass ( $\mathrm{Li}$ et al. 2010).

Room temperature ionic liquid 1-ethyl-3-methylimidazolium acetate [C2mim][OAc] has proved to be particularly effective at dissolution of cellulose, hemicellulose and lignin from switchgrass, corn stover and eucalyptus (Singh et al. 2009). A combination of electrostatic and hydrogen-bonding interactions between ionic liquid and the plant polymers has been proposed as 
(a)
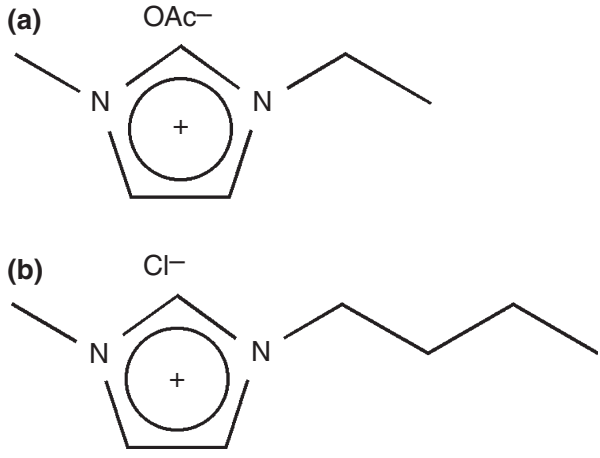

Figure 1 lonic liquids discussed in this study: 1-ethyl-3-methylimidazolium acetate (a); 1-butyl-3-methylimidazolium chloride (b).

dissolution mechanism (Remsing et al. 2006; Sun et al. 2009). However, ionic liquids have been shown to inhibit enzymatic hydrolysis of cellulose (Turner et al. 2003, 2004; Docherty and Kulpa 2005). Therefore, microbes tolerant to ionic liquids may be valuable as sources of glycoside hydrolase enzymes that tolerate residual ionic liquid remaining in biomass. Ionic liquids have been reported to be toxic at low levels $(<1 \% \mathrm{v} / \mathrm{v})$ to both prokaryotes and eukaryotes; however, there are a few reports of high levels of tolerance by specific bacterial and fungal species (Docherty and Kulpa 2005; Petkovic et al. 2009). To identify ionic liquid-tolerant microbes that may be relevant to biomass deconstruction, we performed enrichments in the presence of $[\mathrm{C} 2 \mathrm{mim}][\mathrm{OAc}]$ in liquid cultures with inocula from lignocellulose-deconstructing environments and in solid-state cultures under simulated compost conditions. Here, we report that these enrichments are often dominated by Aspergillus populations and that multiple Aspergillus strains isolated from these lignocellulosedeconstructing environments grow in the presence of high levels of ionic liquids. Additionally, we report the activity of endoglucanases and xylanases secreted by one of these strains in the presence of ionic liquids.

\section{Materials and methods}

\section{Chemicals}

All chemicals were reagent grade and were obtained from Sigma (St Louis, MO, USA) unless otherwise noted and used as received.

Isolation of microbes with $[\mathrm{C} 2 \mathrm{mim}][\mathrm{OAc}]$ as sole carbon source

[C2mim][OAc] $\left(1 \% \mathrm{v} / \mathrm{v}\right.$ or $\left.60 \mathrm{mmol} \mathrm{l}^{-1}\right)$ was added to $50 \mathrm{ml}$ of IL media $\left(0 \cdot 3 \mathrm{~g} \mathrm{l}^{-1} \mathrm{Na}_{2} \mathrm{HPO}_{4}, 0 \cdot 4 \mathrm{~g} \mathrm{l}^{-1} \mathrm{KH}_{2} \mathrm{PO}_{4}\right.$,
$0.2 \mathrm{~g} \mathrm{l}^{-1} \quad \mathrm{NH}_{4} \mathrm{Cl}, \quad 0.04 \mathrm{~g} \mathrm{l}^{-1} \quad \mathrm{MgSO}_{4}, \quad 0.02 \mathrm{~g} \mathrm{l}^{-1} \quad \mathrm{CaCl}_{2}$, $0.002 \mathrm{~g} \mathrm{l}^{-1} \mathrm{FeCl}_{3} ; \mathrm{pH} 7 \cdot 0$ ) in a 250-ml Erlenmeyer flask and then inoculated with c. $50 \mathrm{mg}$ of green waste compost obtained from Grover Soil Solutions in Zamora, CA, USA (Allgaier et al. 2010). The flask was shaken at 150 rev $\min ^{-1}$ for 4 days at $37^{\circ} \mathrm{C}$, after which fungal growth was evident. Five millilitres of this enrichment was inoculated into a second 250-ml Erlenmeyer flask with $50 \mathrm{ml}$ of IL media/1\% [C2mim] [OAc] and shaken for 4 days at $37^{\circ} \mathrm{C}$. A second passage of the enrichment was performed under identical conditions, and then, $100 \mu \mathrm{l}$ of the enrichment was spread onto $1.5 \%$ agar plates containing IL media/1\% [C2mim][OAc] and the plates incubated at $37^{\circ} \mathrm{C}$ for days. After 2 days, fungal spores were sampled with an inoculating loop and streaked onto $1.5 \%$ agar/IL media/1\% [C2mim][OAc] plates. These plates were incubated for 2 days, and then, the fungal spores were inoculated into potato dextrose broth for 3 days of growth. The absence of bacterial contamination was confirmed microscopically and the identity of the isolated fungal strain determined by DNA isolation and PCR amplification of the ITS1-5.8S-ITS2 region using primers 5'-TCCGTAGGTGAACCTGCGG-3' (ITS1) and 5'-TCCT CCGCTTATTGATATGC-3' (ITS4) (Gardes and Bruns 1993). An identical enrichment was performed at $30^{\circ} \mathrm{C}$; however, only bacterial colonies were observed in the agar plates. Enrichments were performed under the same conditions (37 and $30^{\circ} \mathrm{C}$ ) as described above with soil from a garden in Berkeley, CA, USA, and decaying wood collected from Mount Tamalpais State Park, Mill Valley, CA, USA, affording four additional fungal strains (see Results). All of these fungal strains were maintained on potato dextrose agar slants at $4^{\circ} \mathrm{C}$.

\section{Identification of fungi tolerant to $[\mathrm{C} 2 \mathrm{mim}][\mathrm{OAc}]$ from a compost culture collection}

Fungi were isolated from green waste compost obtained from Grover Soil Solutions located in Zamora (DeAngelis et al. 2010). Three grams of compost was suspended in $30 \mathrm{ml}$ of a $5-\mathrm{mmol}^{-1} \mathrm{NaCl}$ solution in a $50-\mathrm{ml}$ conical tube and vortexed for $3 \mathrm{~min}$. Serial dilutions of the supernatant were spread on a variety of solid media (Luria-Bertini, potato dextrose, typtic soy broth) and cultured at $37^{\circ} \mathrm{C}$ for $1-3$ days. Fungal isolates were identified by morphology and were restreaked three times on solid media to ensure the colonies were pure. Isolates were then tested for their ability to grow in LB, giving 19 fungi in the compost culture collection. Fungi tolerant to [C2mim][OAc] from this collection were identified by inoculating $5 \mu \mathrm{l}$ of cultures grown overnight in LB media into 96-well plates containing $200 \mu \mathrm{l}$ of LB media with 
$5 \%$ [C2mim] $[\mathrm{OAc}]$, and growing the cultures for 5 days at $37^{\circ} \mathrm{C}$.

Solid-state culturing of compost and switchgrass amended with $[\mathrm{C} 2 \mathrm{mim}][\mathrm{OAc}]$

Milled switchgrass was wet with sterile distilled water to a targeted moisture content of $400 \%$ dry basis ( $80 \%$ wet basis) and allowed to equilibrate at $4^{\circ} \mathrm{C}$ overnight. Switchgrass was then mixed with the appropriate amount of [C2mim] [OAc] to achieve $0,2,4,6,8$ and $11 \%$ ionic liquid, based on wet weight. Immediately before loading bioreactors, green waste compost was mixed into each batch of switchgrass at a loading rate of $10 \%$ by dry weight.

Bioreactors and respiration measurements for solidstate cultures have been described previously (Reddy et al. 2009). Briefly, for each treatment, three bioreactors with a 0.2-1 working volume were loaded with $10 \mathrm{~g}$ dry weight of the corresponding switchgrass/[C2mim] [OAc]/compost mixture. Air was supplied to each bioreactor at $20 \mathrm{ml} \mathrm{min}^{-1}$ and incubations ran for 7 days. The incubator temperature was maintained at $30^{\circ} \mathrm{C}$ for 3 days, ramped to $55^{\circ} \mathrm{C}$ over 1 day and held at $55^{\circ} \mathrm{C}$ for 3 days. Temperature was monitored with a $\mathrm{HOBO}$ data logger (Onset Computer Corporation, Bourne, MA, USA).

Carbon dioxide concentration was measured on the influent and effluent air of the reactors using an infrared $\mathrm{CO}_{2}$ sensor (Vaisala, Woburn, MA, USA), and flow was measured with a thermal mass flow meter (Aalborg, Orangeburg, NY, USA). Carbon dioxide and flow data were recorded every $20 \mathrm{~min}$ using a data acquisition system (Reddy et al. 2009). Carbon dioxide evolution rates (CER) were calculated from mass balances on the reactors according to the following equation:

$$
\mathrm{CER}=F\left(\mathrm{CO}_{2, \mathrm{OUT}}-\mathrm{CO}_{2, \mathrm{IN}}\right)
$$

where $F$ is the air flow rate (mg air day ${ }^{-1} \mathrm{gdw}^{-1}$ ), $\mathrm{CO}_{2, \mathrm{OUT}}$ and $\mathrm{CO}_{2, \mathrm{IN}}$ are the concentrations of carbon dioxide in the effluent and influent air, respectively ( $\mathrm{mg} \mathrm{CO}_{2} \mathrm{mg} \mathrm{air}^{-1}$ ). Numerical integration of CER results to find cumulative carbon dioxide evolution (cCER) was performed using KaleidaGraph ver. 4.0 (Synergy Software, Reading, PA, USA).

Fungal hyphae were sampled from bioreactors with visible fungal mats, which included treatments with 2, 4 and $6 \%$ [C2mim] [OAc] (Fig. 3). DNA was extracted from the hyphae with cetyl trimethylammonium bromide and bead beating, as described previously (Allgaier et al. 2010). DNA was amplified with ITS1/ITS4 primers (described above) and cloned into Escherichia coli using a TOPO TA cloning kit (Invitrogen, Carlsbad, CA, USA). Sequenced inserts were assembled, trimmed and aligned by a BLAST search with Geneious 4.8.5 (http://www.geneious.com).

\section{Radial growth assay in the presence of $[\mathrm{C} 2 \mathrm{mim}][\mathrm{OAc}]$}

Aspergillus strains JF1 (A. fumigatus), JF4 (A. ustus) and UCDF1 (A. oryzae) were grown on potato dextrose agar slants, and $5 \mathrm{ml}$ of sterile water added to each to generate a spore suspension $\left(10^{6}-10^{7}\right.$ spores $\left.\mathrm{ml}^{-1}\right)$. Fifty microlitres of the spore suspension was pipetted onto $1.5 \%$ agar containing IL media and varying amounts of $[\mathrm{C} 2 \mathrm{mim}][\mathrm{OAc}]$ and $[\mathrm{C} 4 \mathrm{mim}][\mathrm{Cl}]$ as described in the Results section. Plates inoculated with spores from strains JF4 and UCDF1 were incubated at $30^{\circ} \mathrm{C}$ for 4 days, and plates inoculated with spores from strain JF1 were incubated at $37^{\circ} \mathrm{C}$ for 4 days. All plate assays were performed in triplicate.

\section{Enzymatic activity in supernatants of strain JF1 grown on biomass substrates}

Spores of strain A. fumigatus JF1 were inoculated into $50 \mathrm{ml}$ of potato dextrose broth and grown at $37^{\circ} \mathrm{C}$ for 3 days. After 3 days of growth, $5 \mathrm{ml}$ of spores was inoculated into $250-\mathrm{ml}$ Erlenmeyer flasks containing $50 \mathrm{ml}$ of IL media and $1 \% \mathrm{w} / \mathrm{v}$ of biomass substrates (Avicel, birchwood xylan, corn switchgrass, corn stover) as described in the Results section. These cultures were shaken for 3 days at $37^{\circ} \mathrm{C}$ and the cultures filtered through MiraCloth $^{\mathrm{TM}}$ to separate culture supernatants and fungal mycelia. Endoglucanase and xylanase activities were measured using carboxymethylcellulose and birchwood xylan, respectively, as substrates. Reactions were incubated for $30 \mathrm{~min}$ at $50^{\circ} \mathrm{C}$ in $100 \mathrm{mmol} \mathrm{l}^{-1} \mathrm{NaOAc}$ pH 5.0 buffer and sugar release measured by DNS assay (Xiao et al. 2005; Datta et al. 2010). To assess the stability of the endoglucanases and xylanases in the presence of [C2mim] [OAc], the culture supernatant was diluted $1: 2$ in $100 \mathrm{mmol} \mathrm{l}^{-1} \mathrm{NaOAc} \mathrm{pH} \quad 5 \cdot 0$ with 0 and $10 \%$ [C2mim] [OAc] and incubated for $12 \mathrm{~h}$ at $50^{\circ} \mathrm{C}$. Aliquots were removed at 0,6 and $12 \mathrm{~h}$ and assayed for activity as described earlier. All assays were performed in triplicate.

\section{Results}

Microbial isolates enriched with $[\mathrm{C} 2 \mathrm{mim}][\mathrm{OAc}]$ as sole carbon source

Initial studies focused on liquid culture enrichment of microbes from lignocellulose-deconstructing environments using $[\mathrm{C} 2 \mathrm{mim}][\mathrm{OAc}]$ as the sole carbon source. Inoculation of minimal media containing $1 \%(\mathrm{v} / \mathrm{v})$ [C2mim] [OAc] with green waste compost at $37^{\circ} \mathrm{C}$ 
produced fungal growth in the enrichment culture. After successive transfers in liquid media, the fungal-dominated culture was plated onto agar containing $1 \%$ [C2mim] [OAc]. A fungal isolate with typical Aspergillus morphology was obtained, and the amplicon obtained using primers designed to amplify the fungal ITS1-5.8SITS2 sequence was identical to the sequences obtained for strains of A. fumigatus (Table 1). Fungal isolates of identical morphology were also obtained from enrichments performed under the same conditions with garden soil and decaying wood at $37^{\circ} \mathrm{C}$; PCR amplification of the same region also demonstrated that these isolates had sequences nearly identical to characterized strains of A. fumigatus. Complementary enrichments were performed with the same media and inocula at $30^{\circ} \mathrm{C}$. In contrast to the $37^{\circ} \mathrm{C}$ isolations, a strain with an identical sequence to A. fumigatus was only isolated from the $30^{\circ} \mathrm{C}$ garden soil enrichment. Enrichment with decaying wood as inoculum afforded a microbial isolate with a morphology and an amplified sequence (99\% identical) consistent with its description as Aspergillus ustus. In contrast, an enrichment with green waste compost at $30^{\circ} \mathrm{C}$ afforded bacterial colonies. No microbial growth was observed in companion enrichments with 1-butyl-4-methylimidazolium chloride $([\mathrm{C} 4 \mathrm{~min}][\mathrm{Cl}])$, another commonly used ionic liquid in biomass pretreatment, as the sole carbon source (Remsing et al. 2006; Fort et al. 2007).

Fungal tolerance to $[\mathrm{C} 2 \mathrm{mim}][\mathrm{OAc}]$ was also tested by establishing an isolate collection of fungi from the same green waste compost sample described earlier. From enrichments on various media, 19 fungal isolates were obtained. These isolates were cultured in 96-well plates in LB media in the presence of varying amounts of $[\mathrm{C} 2 \mathrm{mim}][\mathrm{OAc}]$. Of these fungal isolates, only one grew in $>1 \%$ [C2mim] [OAc]. Its ITS1-5.8S-ITS2 amplicon was identical to the A. fumigatus isolates previously obtained by enrichment with [C2mim] [OAc] (Table 1).

\section{Solid-state cultures in the presence of [C2mim] [OAc]}

The enrichment of Aspergilli in the presence of [C2mim] $[\mathrm{OAc}]$ was further demonstrated by performing solid-state incubations with compost as inoculum and switchgrass as substrate. Microbial community analysis of a simulated composting incubation with the same compost inoculum and switchgrass as the sole carbon source cultivated a diverse microbial community dominated by bacteria (Allgaier et al. 2010). A peak in respiration was observed after the temperature was ramped to $55^{\circ} \mathrm{C}$, demonstrating the presence of thermophiles in the inoculum (Allgaier et al. 2010). Under these identical conditions, respiration profiles were significantly altered with [C2mim] [OAc] amendment. Lag time increased and cCER decreased with increasing ionic liquid concentration (Fig. 2). For treatments with $>0 \%$ [C2mim] [OAc], there was no increase in activity during the thermophilic phase of the incubation, demonstrating only mesophilic activity in the presence of ionic liquid. Above 8\% [C2mim] $[\mathrm{OAc}]$, there was no measurable microbial activity. Treatments with 2, 4 and $6 \%$ [C2mim] [OAc] had fungal mats on the surface of the switchgrass (Fig. 3). The density of the mat increased with increasing ionic liquid between 2 and $4 \%$. Thirty-three clones were obtained by PCR amplification of the ITS1-5.8S-ITS2 region of DNA extracted from these fungal mats. Sequences of the majority of these clones were closely related to Aspergillus strains (A. niger, A. oryzae, A. flavus) confirming the resistance of Aspergilli to high levels of [C2mim][OAc] (Table 2). Lichtheimia ramosa, a saprotrophic fungi (AlastrueyIzquierdo et al. 2010), was also present in the bioreactor

Table 1 lonic liquid-tolerant fungal isolates from lignocellulose-deconstructing environments

\begin{tabular}{|c|c|c|c|}
\hline Strain & Inoculum & Enrichment conditions & Fungal identification*,$\dagger$ \\
\hline JF1 & Green waste compost & $1 \%[\mathrm{C} 2 \mathrm{mim}][\mathrm{OAC}] / \mathrm{IL}$ media, $37^{\circ} \mathrm{C}$ & Aspergillus fumigatus (HQ882183) \\
\hline JF4 & Garden soil & $1 \%[\mathrm{C} 2 \mathrm{mim}][\mathrm{OAc}] / \mathrm{IL}$ media, $30^{\circ} \mathrm{C}$ & Aspergillus ustus (HQ882184) \\
\hline JF5 & Decaying wood & $1 \%[\mathrm{C} 2 \mathrm{mim}][\mathrm{OAc}] / \mathrm{IL}$ media, $30^{\circ} \mathrm{C}$ & A. fumigatus (HQ882185) \\
\hline JF6 & Garden soil & $1 \%[\mathrm{C} 2 \mathrm{mim}][\mathrm{OAc}] / \mathrm{IL}$ media, $37^{\circ} \mathrm{C}$ & A. fumigatus (HQ882186) \\
\hline JF7 & Decaying wood & $1 \%[\mathrm{C} 2 \mathrm{mim}][\mathrm{OAC}] / \mathrm{IL}$ media, $37^{\circ} \mathrm{C}$ & A. fumigatus (HQ882187) \\
\hline JF11 & Green waste compost & $\mathrm{LB}$ media, $37^{\circ} \mathrm{C}$ & A. fumigatus (HQ882188) \\
\hline UCDF1 & Green waste compost & Solid state/PD agar, $30^{\circ} \mathrm{C}$ & Aspergillus flavus/oryzaeł, $§(\mathrm{HQ882189)}$ \\
\hline UCDF3 & Green waste compost & Solid state/PD agar, $30^{\circ} \mathrm{C}$ & A. flavus/oryzae§ (HQ882190) \\
\hline UCDF5 & Solid-state bioreactor & Solid state/PD agar, $30^{\circ} \mathrm{C}$ & Lichtheimia ramosa (HQ882191) \\
\hline
\end{tabular}

*Fungal identification was based on $\geq 99 \%$ identity of ITS1-5.8S-ITS2 sequence to known strains.

$\dagger$ Nucleotide accession numbers for isolates deposited in GenBank are in parenthesis.

IIdentification was validated by amplification and sequencing of $\beta$-tubulin gene (100\% identity). For UCDF1, the $\beta$-tubulin sequence was $100 \%$ identical to the A. oryzae RIB40 (Machida et al. 2005).

$\S A$. flavus and A. oryzae cannot be distinguished by sequencing of the ITS1-5.8S-ITS2 region (Kumeda and Asao 1996). 

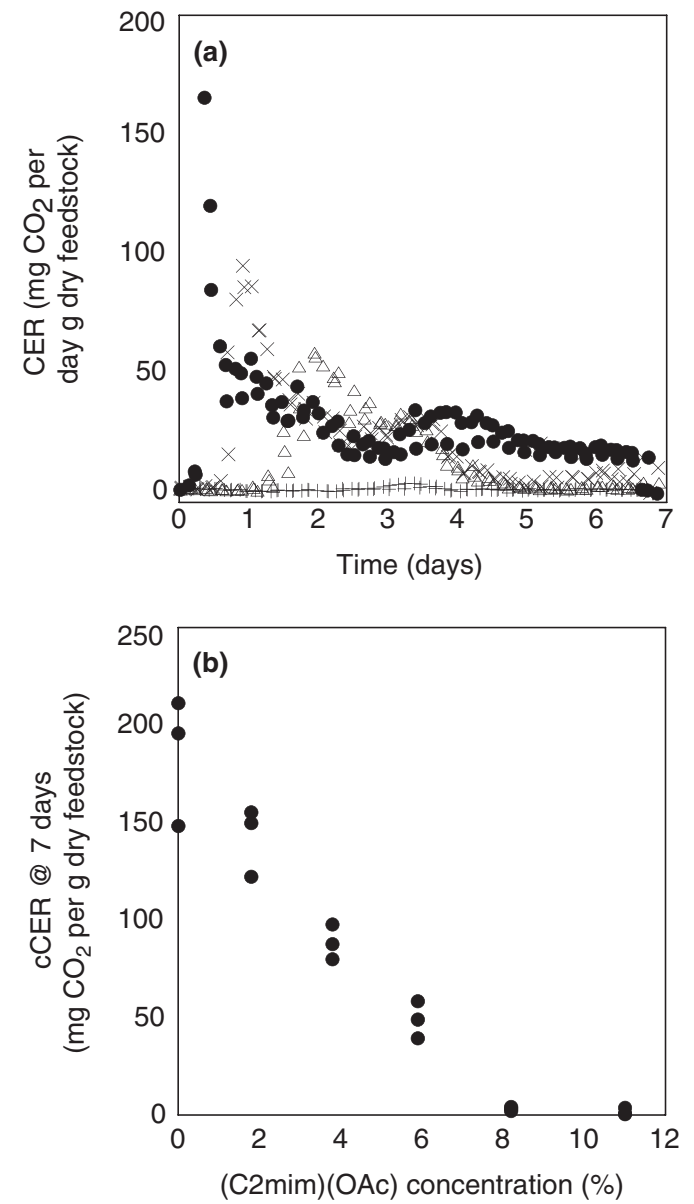

Figure 2 Respiration profiles for solid-state cultures in the presence of [C2mim][OAc]: (a) carbon dioxide evolution rate (CER) over 7 days; (b) cumulative carbon dioxide evolution (CCER) after 7 days. All cultivations were performed in triplicate. $(0,0 \% ; \times, 2 \% ; \triangle, 4 \%$; and $+, 8 \%)$.

with $4 \%[\mathrm{C} 2 \mathrm{mim}][\mathrm{OAc}]$ amendment and was isolated from the same bioreactor (Table 2). Isolates closely related to A. flavus and A. oryzae (UCDF1 and UCDF3) were obtained from the $2 \%$ bioreactor.

\section{Demonstration of IL tolerance of Aspergillus strains}

To determine the extent of ionic liquid tolerance in the isolated Aspergilli, three strains were chosen: strain JF1, JF4 and UCDF1, which represented the range of Aspergillus species enriched in the presence of [C2mim] [OAc] (Table 3). These three strains were incubated on agar plates containing varying levels of $[\mathrm{C} 2 \mathrm{mim}][\mathrm{OAc}]$ and radial growth measured (D'Annibale et al. 2006). In all three cases, radial growth was inhibited at increasing concentrations of $[\mathrm{C} 2 \mathrm{mim}][\mathrm{OAc}]$; however, growth was evident at $10 \%[\mathrm{C} 2 \mathrm{mim}][\mathrm{OAc}]$, consistent with a very
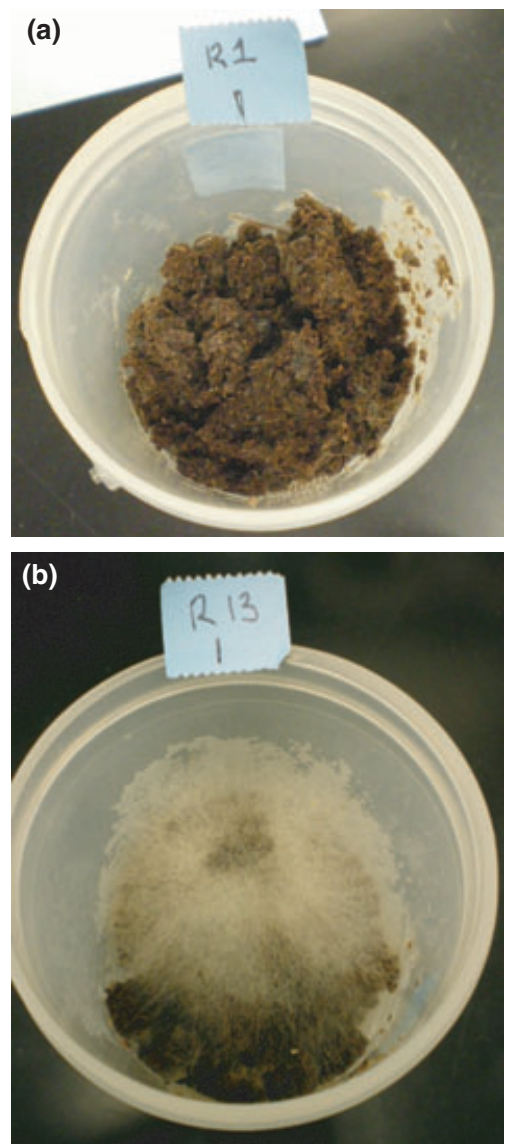

Figure 3 Pictures of solid-state fermentation reactors containing compost and switchgrass after 7 days incubation as described in Materials and methods in the presence of: (a) $0 \%$ [C2mim][OAc]; (b) $4 \%[C 2 \mathrm{mim}][\mathrm{OAc}]$.

Table 2 Identification of PCR products from solid-state fermentation of switchgrass inoculated with green waste compost in the presence of [C2mim] $[\mathrm{OAc}]$

\begin{tabular}{lccl}
\hline $\begin{array}{l}\text { [C2mim][OAC] } \\
\text { amendment }\end{array}$ & $\begin{array}{l}\text { No. of } \\
\text { clones }\end{array}$ & $\begin{array}{l}\text { \% Pairwise } \\
\text { identity }\end{array}$ & $\begin{array}{l}\text { Fungal } \\
\text { identification }\end{array}$ \\
\hline $2 \%$ & 10 & 100 & Aspergillus flavus/oryzae \\
$4 \%$ & 1 & 99.8 & Aspergillus niger \\
& 2 & 100 & Lichtheimia ramosa \\
$6 \%$ & 20 & 100 & A. flavus/oryzae \\
\hline
\end{tabular}

high level of resistance to ionic liquids (Table 3). When these three strains were incubated in plates containing $5 \%$ $[\mathrm{C} 4 \mathrm{mim}][\mathrm{Cl}]$, no growth was observed under the same conditions, indicating that these strains are incapable of growing on $[\mathrm{C} 4 \mathrm{mim}][\mathrm{Cl}]$. However, when $1 \% \mathrm{NaOAc}$ was added to plates containing $5 \%[\mathrm{C} 4 \mathrm{mim}][\mathrm{Cl}]$, radial growth comparable to the radial growth observed for $5 \%$ [C2mim] [OAc] was observed. 
Table 3 Radial growth (diameter in $\mathrm{mm}$ ) of Aspergillus strains in presence of ionic liquid

\begin{tabular}{|c|c|c|c|c|c|c|}
\hline Strain & $1 \% \mathrm{NaOAC}$ & $\begin{array}{l}2 \cdot 5 \%[\mathrm{C} 2 \mathrm{mim}] \\
{[\mathrm{OAc}]}\end{array}$ & $\begin{array}{l}5 \cdot 0 \%[C 2 \mathrm{mim}] \\
{[\mathrm{OAc}]}\end{array}$ & $\begin{array}{l}7 \cdot 5 \%[C 2 \mathrm{mim}] \\
{[\mathrm{OAc}]}\end{array}$ & $\begin{array}{l}10 \%[C 2 \mathrm{mim}] \\
{[\mathrm{OAc}]}\end{array}$ & $\begin{array}{l}5 \%[\mathrm{C} 4 \mathrm{mim}] \\
{[\mathrm{Cl}] / 1 \% \mathrm{NaOAC}}\end{array}$ \\
\hline JF1 & $18 \cdot 0 \pm 0 \cdot 5$ & $13 \cdot 0 \pm 1 \cdot 0$ & $14 \cdot 0 \pm 1 \cdot 0$ & $10 \cdot 0 \pm 0.5$ & $8 \cdot 0 \pm 1 \cdot 0$ & $11 \cdot 0 \pm 0 \cdot 5$ \\
\hline JF4 & $16 \cdot 0 \pm 0 \cdot 5$ & $16 \cdot 0 \pm 1 \cdot 5$ & $10 \cdot 0 \pm 0.5$ & $7 \cdot 5 \pm 0.5$ & $5 \cdot 0 \pm 0.5$ & $10 \cdot 5 \pm 1 \cdot 5$ \\
\hline UCDF1 & $19 \cdot 0 \pm 2 \cdot 0$ & $16 \cdot 0 \pm 1 \cdot 0$ & $13 \cdot 0 \pm 1 \cdot 0$ & $13 \cdot 0 \pm 0 \cdot 5$ & $11 \cdot 0 \pm 0.5$ & $13 \cdot 0 \pm 0.5$ \\
\hline
\end{tabular}

Table 4 Endoglucanase and xylanase activity of Aspergillus fumigatus JF1 supernatants grown on biomass substrates

\begin{tabular}{|c|c|c|c|c|c|c|}
\hline Substrate & Avicel & Xylan & Corn Stover & Switchgrass & $\begin{array}{l}\text { Switchgrass } / 5 \% \\
{[C 2 \mathrm{mim}][\mathrm{OAc}]}\end{array}$ & $\begin{array}{l}\text { Switchgrass } / 5 \% \\
{[\text { C4mim }][\mathrm{Cl}]}\end{array}$ \\
\hline CMC & $N D *$ & $0.27 \pm 0.12 \dagger$ & $0.71 \pm 0.08$ & $1 \cdot 4 \pm 0 \cdot 15$ & $0.04 \pm 0.01$ & $1.7 \pm 0.08$ \\
\hline Xylan & $0.04 \pm 0.01$ & $0.38 \pm 0.04$ & $0.78 \pm 0.14$ & $3 \cdot 3 \pm 0 \cdot 10$ & $0.16 \pm 0.01$ & $4 \cdot 2 \pm 0 \cdot 15$ \\
\hline
\end{tabular}

*Not detected.

$\dagger$ Enzymatic activity expressed in $\mu \mathrm{mol}$ of sugar (glucose or xylose) released $\mathrm{min}^{-1} \mathrm{ml}^{-1}$ of supernatant.

\section{IL tolerance of Aspergillus fumigatus enyzmes in the context of lignocellulose deconstruction}

Of relevance to this work is the impact of ionic liquids on the expression and activity of lignocellulose-deconstructing enzymes. As Aspergillus strains have been extensively employed in deconstructing biomass and enzyme production, the isolation of ionic liquid-tolerant Aspergilli provides an opportunity to directly test the effect of ionic liquids on biomass deconstruction (Grigorevski-Lima et al. 2009). Incubations of the three representative Aspergillus strains (JF1, JF4 and UCDF1) in the presence of biomass substrates indicated that the A. fumigatus JF1 strain growing at $37^{\circ} \mathrm{C}$ possessed significantly higher levels of secreted endoglucanase and xylanase activities in comparison to the A. ustus and A. oryzae, so detailed studies were performed on the A. fumigatus strain (data not shown). Initial growth studies demonstrated that the highest endoglucancase and xylanase activities were obtained for supernatants isolated from A. fumigatus JF1 cultured in the presence of switchgrass; minimal activity in the supernatant was recovered from cultures grown with purified biomass substrates (Avicel, birchwood xylan) (Table 4). When A. fumigatus JF1 was cultivated on switchgrass in the presence of $1 \%[\mathrm{C} 2 \mathrm{mim}][\mathrm{OAc}]$, fungal growth was observed, but no enzymatic activity was detected in the supernatant, consistent with the use of $[\mathrm{C} 2 \mathrm{mim}][\mathrm{OAc}]$ as the primary carbon source. In contrast, in the presence of $1 \%[\mathrm{C} 4 \mathrm{mim}][\mathrm{Cl}] /$ switchgrass, comparable levels of enzymatic activity were recovered in the supernatant compared to the switchgrass-only culture. The levels of endoglucanase and xylanase activities are similar to previously reported results for other strains of A. fumigatus grown on biomass substrates (Stewart et al. 1983; Grigorevski-Lima et al. 2009).
To test the tolerance of the secreted enzymes to ionic liquids, endoglucanase and xylanase assays were performed on the switchgrass-derived supernatant in the presence of increasing levels of [C2mim] [OAc]. Endoglucanase assays in the presence of increasing [C2mim] [OAc] concentration demonstrated that the ionic liquid did inhibit enzymatic activity; however, $43 \%$ of the residual activity was retained at 20\% IL (Fig. 4). Comparable levels of inhibition were also observed for in the xylanase activity assay, although the loss of activity was more pronounced at higher concentrations of $[\mathrm{C} 2 \mathrm{mim}][\mathrm{OAc}]$. Incubating the

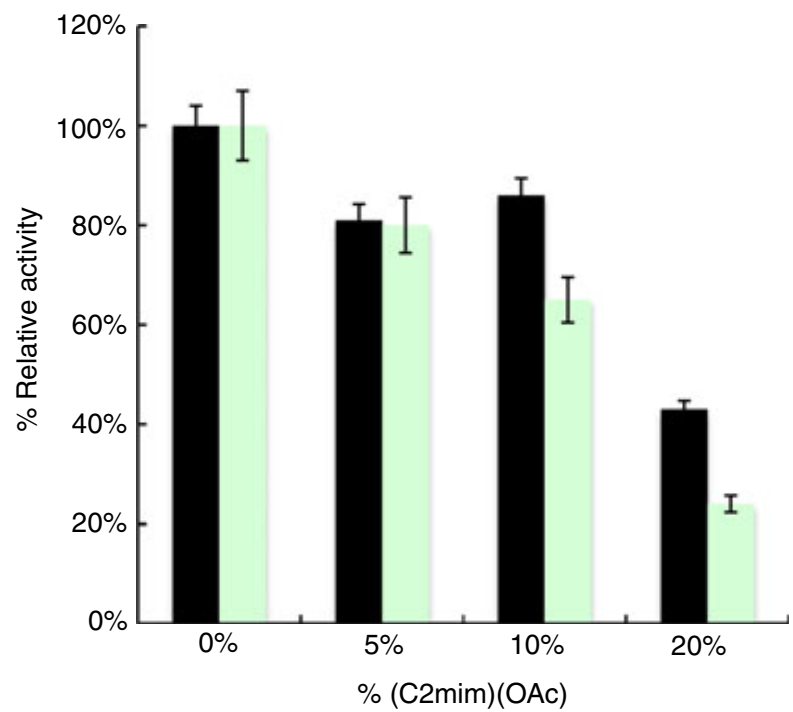

Figure 4 Endoglucanase and xylanase assays in the presence of [C2mim][OAc]. Incubations of Aspergillus fumigatus JF1 supernatant with carboxymethylcellulose and xylan were performed in the presence of varying concentrations of [C2mim][OAc] and release of sugars measured by DNS assay. ( $\square$ ) Endoglucanase and ( ) Xylanase. 
supernatant from strain JF1 in the presence of varying levels of $[\mathrm{C} 2 \mathrm{mim}][\mathrm{OAc}]$ demonstrated that the endoglucanase activity was quite stable in the presence of $[\mathrm{C} 2 \mathrm{mim}][\mathrm{OAc}]$, retaining approximately the same amount of activity after $12 \mathrm{~h}$ in the presence of $10 \%$ [C2mim][OAc] relative to an unamended control. In contrast, xylanase activity was dramatically reduced by incubation in the presence of $10 \%$ [C2mim] [OAc] (Fig. 5a,b).

(a)

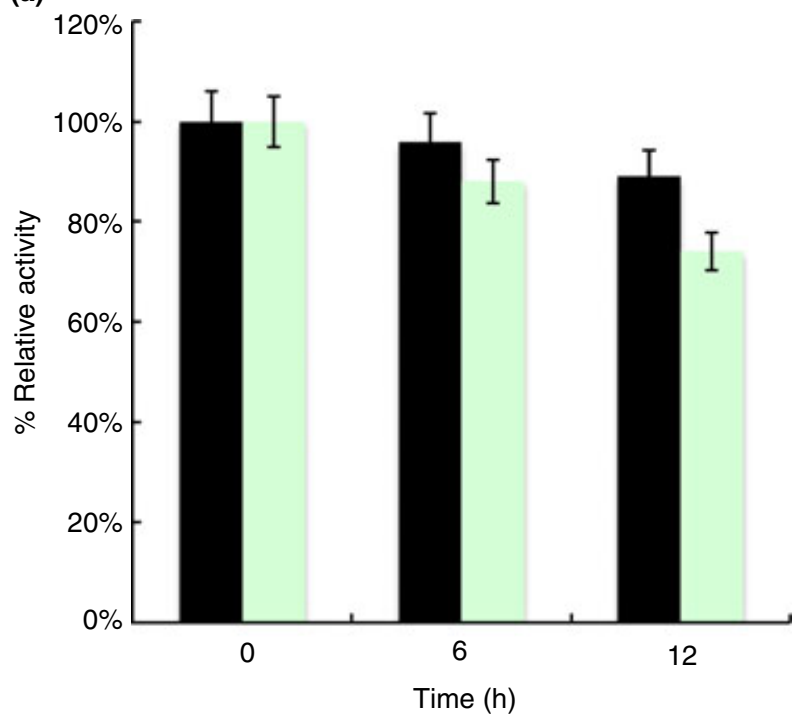

(b)

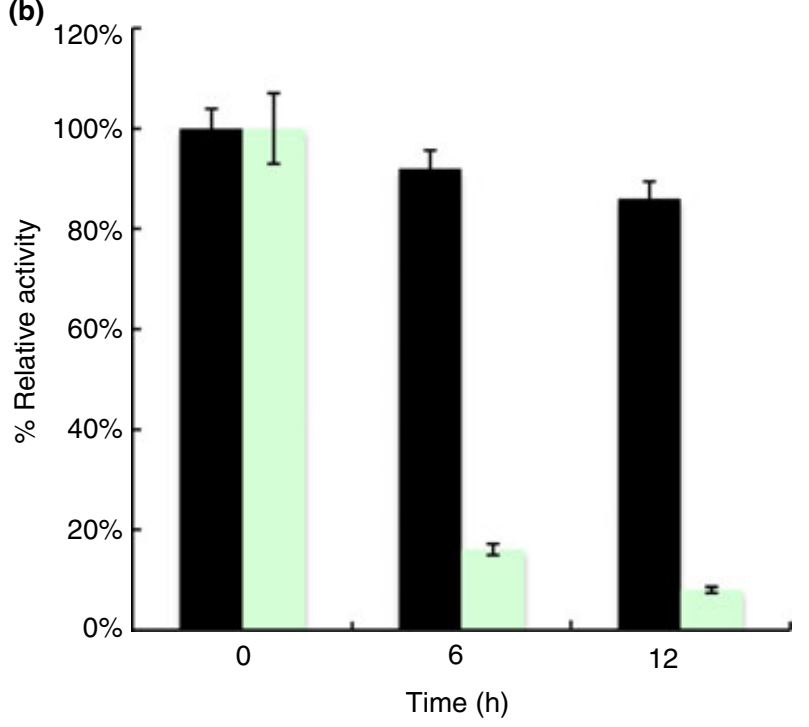

Figure 5 Stability of endoglucanases and xylanases in the presence of [C2mim][OAc]. Aspergillus fumigatus JF1 supernatant was preincubated for $12 \mathrm{~h}$ with varying concentrations of [C2mim][OAc]. Aliquots were removed at 0,6 and $12 \mathrm{~h}$ and assayed for release of sugars from carboxymethylcellulose and xylan: (a) 0\% [C2mim][OAc]; (b) 10\% [C2mim][OAc]. (ם) Endoglucanase and ( ) Xylanase.

\section{Discussion}

We have demonstrated through three different cultivation methods that common Aspergilli isolated from soil and compost possess high tolerances to [C2mim] [OAc] and can use this ionic liquid as their sole carbon source for growth. The absence of growth of these strains in the presence of $[\mathrm{C} 4 \mathrm{mim}][\mathrm{Cl}]$ suggests that the fungi utilize the acetate as the source of carbon; the ability of Aspergillus isolates to grow with acetate as the sole carbon source has been extensively documented (Collins and Kornberg 1960; Armitt et al. 1970; Meijer et al. 2009). These results are also consistent with previous observations that the imidazolium ring is resistant to biodegradation and may persist in the environment (Docherty and Kulpa 2005). The Aspergillus strains described here grow at concentrations of ionic liquid $\left(\leq 0.6 \mathrm{~mol} \mathrm{l}^{-1}\right)$ that are orders of magnitude higher than what has been previously reported for most eukaryotic organisms (Latala et al. 2010). Recently, however, substantial ionic liquid tolerance (up to $0.375 \mathrm{~mol} \mathrm{l}^{-1} \mathrm{IL}$ ) was reported for Penicillium isolates (Petkovic et al. 2009). Therefore, some filamentous fungi may have inherent tolerance to ionic liquids. Although studies of the toxicity of ionic liquids are not extensive, reports have suggested that toxicity is related to oxidative stress response or disruption of cellular membranes (Docherty and Kulpa 2005).

High solids incubations with compost-amended switchgrass yielded a diverse prokaryotic-enriched microbial community in previous studies (Allgaier et al. 2010). A fungal mat was not observed in either the prior study or the treatment in the present study with no ionic liquid. The presence of a fungal mat on switchgrass with [C2mim][OAc] amendment suggests the ionic liquid inhibited the community that would normally establish during switchgrass decomposition and allowed the establishment of fungi, in particular Aspergilli.

Very little respiration was detected in incubations containing ionic liquid under thermophilic conditions. While Aspergillus ssp. have been identified in thermophilic composts (Le Goff et al. 2010), the enriched strains were not able to remain active under thermophilic conditions in the presence of ionic liquids. This may have been because of a number of factors including the thermotolerance of the selected community and their hydrolytic enzymes and the greater potential of the ionic liquids to solubilize polysaccharides in plant and fungal cell walls with increasing temperature.

Previous work on the tolerance of endoglucanases to ionic liquid demonstrated that endoglucanases from hyperthermophiles possessed substantial ionic liquid tolerance, retaining significant enzymatic activity at 30\% [C2mim] [OAc], while a commercial endoglucanase from 
Trichoderma viridie was inactive at [C2mim] [OAc] concentrations $>5 \%$ (Datta et al. 2010). Additionally, commercial enzymatic endoglucanase cocktails obtained from Novozymes showed very low activity in reducing sugar assays with $>10 \%[\mathrm{C} 2 \mathrm{mim}][\mathrm{OAc}]$ (Gladden et al. 2011). Therefore, the endoglucanases secreted by the A. fumigatus strain isolated here, which retain significant residual activity in the presence of $20 \%$ [C2mim] [OAc] and are stable in the presence of $10 \%$ [C2mim] [OAc] at $50^{\circ} \mathrm{C}$, tolerate $[\mathrm{C} 2 \mathrm{mim}][\mathrm{OAc}]$ at concentrations intermediate between commercial fungal enzymes and hyperthermophilic bacterial enzymes and may have application in deconstruction of biomass pretreated with [C2mim][OAc]. The xylanase enzymes secreted by the A. fumigatus strain show much lower stability on the presence of $[\mathrm{C} 2 \mathrm{mim}][\mathrm{OAc}]$. The structural differences between these two types of enzymes from A. fumigatus may be instructive in understanding the stabilization of proteins in the presence of ionic liquids. Interaction of the acetate anion with hydrogen bonds in the protein structure has been proposed as a mechanism for protein denaturation in the presence of [C2mim][OAc] (Kaar et al. 2003). This work also demonstrated that the endoglucanases and xylanases were secreted and were active in the presence of ionic liquid $[\mathrm{C} 4 \mathrm{mim}][\mathrm{Cl}]$ while they were not secreted in the presence of [C2mim] [OAc], consistent with the observation that $A$. fumigatus requires an additional carbon source in the presence of $[\mathrm{C} 4 \mathrm{mim}][\mathrm{Cl}]$, but preferentially grows on $[\mathrm{C} 2 \mathrm{mim}][\mathrm{OAc}]$ in the presence of switchgrass, which is a recalcitrant source of carbon.

\section{Conclusions}

In conclusion, we have shown that liquid and solid-state enrichment cultures in the presence of [C2mim] [OAc] selected for fungal populations, especially Aspergillus species. Aspergillus isolates obtained from these enrichments were capable of growing in the presence of up to $10 \%$ [C2mim] [OAc] and secreted glycoside hydrolase enzymes that were moderately stable to $[\mathrm{C} 2 \mathrm{mim}][\mathrm{OAc}]$. The demonstration that Aspergillus species are tolerant to [C2mim] [OAc] may lead to biotechnological applications that utilize this industrially important fungal genera in the presence of ionic liquids.

\section{Acknowledgements}

Validation of Aspergillus oryzae strain UCDF1 by $\beta$-tubulin sequencing was performed by Dr. Brian Wicks at the University of Texas Health Science Center at San Antonio Fungus Testing Laboratory. Special thanks to Josh Claypool for his assistance at University of CaliforniaDavis. This work was performed as part of the DOE Joint
BioEnergy Institute (http://www.jbei.org) supported by the U.S. Department of Energy, Office of Science, Office of Biological and Environmental Research, through contract DE-AC02-05CH11231 between Lawrence Berkeley National Laboratory and the U.S. Department of Energy.

\section{References}

Alastruey-Izquierdo, A., Hoffmann, K., de Hoog, G.S., Rodriguez-Tudela, J.L., Voigt, K., Bibashi, E. and Walther, G. (2010) Species recognition and clinical relevance of the zygomycetous genus Lichtheimia (syn Absidia Pro Parte, Mycocladus). J Clin Microbiol 48, 2154-2170.

Allgaier, M., Reddy, A., Park, J.I., Ivanova, N., D’Haeseleer, P., Lowry, S., Sapra, R., Hazen, T.C. et al. (2010) Targeted discovery of glycoside hydrolases from a switchgrassadapted compost community. PLoS ONE 5(1), e8812.

Armitt, S., Roberts, C.F. and Kornberg, H.L. (1970) Role of isocitrate lyase in Aspergillus nidulans. FEBS Lett 7, 231234.

Blanch, H.W., Adams, P.D., Andrews-Cramer, K.M., Frommer, W.B., Simmons, B.A. and Keasling, J.D. (2008) Addressing the need for alternative transportation fuels: the Joint BioEnergy Institute. ACS Chem Biol 3, 17-20.

Collins, J.F. and Kornberg, H.L. (1960) Metabolism of C-2 compounds in micro-organims. 4. Synthesis of cell materials from acetate by Aspergillus niger. Biochem J 77, 430-438.

D’Annibale, A., Rosetto, F., Leonardi, V., Federici, F. and Petruccioli, M. (2006) Role of autochthonous filamentous fungi in bioremediation of a soil historically contaminated with aromatic hydrocarbons. Appl Environ Microbiol 72, $28-36$.

Datta, S., Holmes, B., Park, J.I., Chen, Z.W., Dibble, D.C., Hadi, M., Blanch, H.W., Simmons, B.A. et al. (2010) Ionic liquid tolerant hyperthermophilic cellulases for biomass pretreatment and hydrolysis. Green Chem 12, 338-345.

DeAngelis, K.M., Gladden, J.M., Allgaier, M., D’Haeseleer, P., Fortney, J.L., Reddy, A., Hugenholtz, P., Singer, S.W. et al. (2010) Strategies for enhancing the effectiveness of metagenomic-based enzyme discovery in lignocellulolytic microbial communities. Bioenergy Res 3, 146-158.

Docherty, K.M. and Kulpa, C.F. (2005) Toxicity and antimicrobial activity of imidazolium and pyridinium ionic liquids. Green Chem 7, 185-189.

Fort, D.A., Remsing, R.C., Swatloski, R.P., Moyna, P., Moyna, G. and Rogers, R.D. (2007) Can ionic liquids dissolve wood? Processing and analysis of lignocellulosic materials with 1-n-butyl-3-methylimidazolium chloride Green Chem 9, 63-69.

Gardes, M. and Bruns, T.D. (1993) ITS primers with enhanced specificity for basdiomycetes - application to the identification of mycorrhizae and rusts. Mol Ecol 2, 113118. 
Gladden, J.M., Allgaier, M., Miller, C.S., Hazen, T.C., VanderGheynst, J.S., Hugenholtz, P., Simmons, B.A. and Singer, S.W. (2011) Community dynamics and glycoside hydrolase activities of thermophlic bacterial consortia adapted to switchgrass. Submitted.

Gomez, L.D., Steele-King, C.G. and McQueen-Mason, S.J. (2008) Sustainable liquid biofuels from biomass: the writing's on the walls. New Phytol 178, 473-485.

Grigorevski-Lima, A.L., Da Vinha, F.N.M., Souza, D.T., Bispo, A.S.R., Bon, E.P.S., Coelho, R.R.R. and Nascimento, R.P. (2009) Aspergillus fumigatus: thermophilic and acidophilic endoglucanases. Appl Biochem Biotechnol 155, 321-329.

Kaar, J.L., Jesionowski, A.M., Berberich, J.A., Moulton, R. and Russell, A.J. (2003) Impact of ionic liquid physical properties on lipase activity and stability. J Am Chem Soc 125, 4125-4131.

Kumeda, Y. and Asao, T. (1996) Single-strand conformation polymorphism analysis of PCR-amplified ribosomal DNA internal transcribed spacers to differentiate species of Aspergillus section Flavi. Appl Environ Microbiol 62, 29472952.

Latala, A., Nedzi, M. and Stepnowski, P. (2010) Toxicity of imidazolium ionic liquids towards algae. Influence of salinity variations. Green Chem 12, 60-64.

Le Goff, O., Bru-Adan, V., Bacheley, H., Godon, J.J. and Wery, N. (2010) The microbial signature of aerosols produced during the thermophilic phase of composting. J Appl Microbiol 108, 325-340.

Li, C.L., Knierim, B., Manisseri, C., Arora, R., Scheller, H.V., Auer, M., Vogel, K.P., Simmons, B.A. et al. (2010) Comparison of dilute acid and ionic liquid pretreatment of switchgrass: biomass recalcitrance, delignification and enzymatic saccharification. Bioresour Technol 101, 49004906.

Machida, M., Asai, K., Sano, M., Tanaka, T., Kumagai, T., Terai, G., Kusumoto, K.I., Arima, T. et al. (2005) Genome sequencing and analysis of Aspergillus oryzae. Nature 438, $1157-1161$.

Meijer, S., de Jongh, W.A., Olsson, L. and Nielsen, J. (2009) Physiological characterisation of acuB deletion in Aspergillus niger. Appl Microbiol Biotechnol 84, 157-167.
Petkovic, M., Ferguson, J., Bohn, A., Trindade, J., Martins, I., Carvalho, M.B., Leitao, M.C., Rodrigues, C. et al. (2009) Exploring fungal activity in the presence of ionic liquids. Green Chem 11, 889-894.

Reddy, A.P., Jenkins, B.M. and VanderGheynst, J.S. (2009) The critical moisture range for rapid microbial decomposition of rice straw during storage. Trans ASABE 52, 673-677.

Remsing, R.C., Swatloski, R.P., Rogers, R.D. and Moyna, G. (2006) Mechanism of cellulose dissolution in the ionic liquid 1-n-butyl-3-methylimidazolium chloride: a C-13 and Cl-35/37 NMR relaxation study on model systems. Chem Commun, 12, 1271-1273.

Singh, S., Simmons, B.A. and Vogel, K.P. (2009) Visualization of biomass solubilization and cellulose regeneration during ionic liquid pretreatment of switchgrass. Biotechnol Bioeng 104, 68-75.

Stewart, J.C., Lester, A., Milburn, B. and Parry, J.B. (1983) Xylanase and cellulase production by Aspergillus fumigatus Fresenius. Biotechnol Lett 5, 543-548.

Sun, N., Rahman, M., Qin, Y., Maxim, M.L., Rodriguez, H. and Rogers, R.D. (2009) Complete dissolution and partial delignification of wood in the ionic liquid 1-ethyl-3methylimidazolium acetate. Green Chem 11, 646-655.

Swatloski, R.P., Spear, S.K., Holbrey, J.D. and Rogers, R.D. (2002) Dissolution of cellulose with ionic liquids. J Am Chem Soc 124, 4974-4975.

Turner, M.B., Spear, S.K., Huddleston, J.G., Holbrey, J.D. and Rogers, R.D. (2003) Ionic liquid salt-induced inactivation and unfolding of cellulase from Trichoderma reesei. Green Chem 5, 443-447.

Turner, M.B., Spear, S.K., Holbrey, J.D. and Rogers, R.D. (2004) Production of bioactive cellulose films reconstituted from ionic liquids. Biomacromolecules 5, 13791384.

Xiao, Z.Z., Storms, R. and Tsang, A. (2005) Microplate-based carboxymethylcellulose assay for endoglucanase activity. Anal Biochem 342, 176-178.

Yang, B. and Wyman, C.E. (2008) Pretreatment: the key to unlocking low-cost cellulosic ethanol. Biofuels Bioproducts Biorefining 2, 26-40. 


\section{DISCLAIMER}

This document was prepared as an account of work sponsored by the United States Government. While this document is believed to contain correct information, neither the United States Government nor any agency thereof, nor The Regents of the University of California, nor any of their employees, makes any warranty, express or implied, or assumes any legal responsibility for the accuracy, completeness, or usefulness of any information, apparatus, product, or process disclosed, or represents that its use would not infringe privately owned rights. Reference herein to any specific commercial product, process, or service by its trade name, trademark, manufacturer, or otherwise, does not necessarily constitute or imply its endorsement, recommendation, or favoring by the United States Government or any agency thereof, or The Regents of the University of California. The views and opinions of authors expressed herein do not necessarily state or reflect those of the United States Government or any agency thereof or The Regents of the University of California.

Ernest Orlando Lawrence Berkeley National Laboratory is an equal opportunity employer. 